\title{
Sigur Rós e o projeto "Valtari Mystery Film Experiment": por uma reflexão enunciativa em videoclipes musicais ${ }^{1}$
}

\section{LIENE NUNES SADDI}

\section{Resumo}

O presente artigo busca propor um espaço enunciativo para a análise de videoclipes musicais enquanto objetos da cultura visual incorporados ao universo da arte contemporânea, através do estudo de caso do projeto "Valtari Mystery Film Experiment” (2012), do grupo musical islandês Sigur Rós. Para isto, promove aproximações entre os campos da comunicação e os domínios teóricos das artes visuais, traçando pontos de observação que partem da subjetividade

Palavras-chave: Videoclipes, regime contemporâneo, cultura visual dos músicos e diretores envolvidos até chegarem a questões de reorganização da circulação de obras na contemporaneidade. 


\section{Sigur Rós and the "Valtari Mystery Film Experiment" project: for an enunciative reflection on music videos}

\section{LIENE NUNES SADDI}

\section{Abstract}

This paper seeks to propose an enunciative space to analyze music video clips as objects of visual culture incorporated into the universe of contemporary art, through the case study of the project "Valtari Mystery Film Experiment" (2012), created by the post-rock Icelandic band Sigur Rós. To achieve this, it brings together the fields of communication and the theoretical domains of Visual Arts, by tracking observation points that go from the subjectivities of musicians and directors to issues of reorganizing the circulation of contemporary works.
Keywords:

Music video clips, contemporary regime, visual culture 


\section{Sigur Rós y el proyecto "Valtari Mystery Film Experiment": por una reflexión enunciativa en los videoclips musicales}

\section{LIENE NUNES SADDI}

\section{Resumen}

El presente artículo busca abrir un espacio enunciativo para el análisis de los videoclips musicales en cuanto objetos de la cultura visual e incorporados al universo del arte contemporáneo, ello, a través del estudio de caso del proyecto "Valtari Mystery Film Experiment" (2012), del grupo musical islandés Sigur Rós. Para lo anterior, se promueven aproximaciones entre los campos de la comunicación y los dominios teóricos de las artes visuales, trazando puntos de observación que nacen de la subjetividad de los músicos y directores circunscritos, ocupando hasta cuestiones de reorganización en la poráneo, cultura visual circulación de las obras en la contemporaneidad. 


\section{O videoclipe enquanto campo acadêmico}

Nas últimas décadas, os espaços de diálogos artísticos e acadêmicos assistiram a uma apreensão - mesmo que de forma pontual - de parte da produção de videoclipes musicais como objetos de arte. Produtos visuais geralmente vinculados ao lançamento de um álbum musical, atrelados pela indústria fonográfica à divulgação comercial de cantores e bandas, os videoclipes musicais ainda assim integram um campo enunciativo múltiplo e diversificado, onde é possível localizar desvios em proposições estéticas em meio ao grosso dos objetos culturais produzidos. Isto pode ser observado em momentos específicos desde a invenção dos aparelhos para registro e edição de vídeo na década de 1960, com as parcerias entre músicos e artistas visuais como Andy Warhol e a banda The Velvet Underground, Nam June Paik e Laurie Anderson, e um pouco mais à frente, a partir dos anos 1980, nas parcerias entre músicos e cineastas, incluindo Michel Gondry, Spike Jonze e Romain Gavras.

Uma instituição em que estes videoclipes aparecem de maneira recorrente é o MoMA (The Museum of Modern Art), em Nova York, seja através de seu acervo - em 2008 o museu recebeu uma doação de quarenta vídeos produzidos por David Bowie em mais de quatro décadas de carreira - seja através das mostras organizadas, de maneira isolada nos anos 1980 e com maior regularidade a partir dos anos 2000. A exposição "Looking at Music" (2008) - primeira de uma série de três mostras que foram organizadas nos anos subsequentes -, por exemplo, partiu da proposta curatorial de Barbara London ao indicar que a música atuou como campo pioneiro de experimentações interdisciplinares nos primeiros momentos da videoarte. Outros países - como Itália, Alemanha, Estados Unidos e Brasil - também passaram a organizar, ou a receber 
circulações de mostras similares, reforçando institucionalmente a inscrição desta produção no campo da arte.

Muito se discutiu sobre a existência do museu em um determinado momento histórico como legitimador de uma obra de arte, ditando através da figura de um curador ou da crítica o que é valorado como artístico, e o que pode passar da 'potência criativa' à esfera do mercado. Contudo, na passagem, durante meados do século XX, do sistema 'curador-marchand' para um sistema essencialmente comunicativo e estruturado comercialmente em rede (CAUQUELIN, 2005), o que o museu passa a exibir é o seu próprio valor de espetáculo, também indicado por Hal Foster:

Mais e mais, a função mnemônica do museu é repassada ao arquivo eletrônico, que pode ser acessado de quase qualquer lugar, enquanto a função visual é dada não apenas à forma de exposição de arte, mas ao prédio do museu como espetáculo, isto é, como imagem a ser circulada pela mídia a serviço da igualdade de marcas e capital cultural (FOSTER, 2008, p. 190).

No corpus de reflexões localizadas sobre o videoclipe como obra de arte visual ainda se encontra uma discussão de teor anacrônico, pautada sobre como este tipo de objeto pode ou não apresentar elementos 'dissolvidos' da videoarte em âmbito televisivo. Discussões que remetem a um momento datado, onde o videoclipe ainda era pensado de maneira praticamente exclusiva para circulação em emissoras de TV, e onde o artista musical, para existir comercialmente, ainda era necessariamente ligado a grandes gravadoras e selos musicais globalmente constituídos. Esta reflexão, apesar de importante na década de 1990 e na legitimação do videoclipe enquanto detentor de poéticas, hoje carrega deficiências no entendimento de relações: academicamente, ela não dá mais conta das mudanças estruturais ocorridas com o advento da internet e com a distribuição de objetos culturais em redes descentralizadas de comunicação. E essencialmente, não acompanha o entendimento deste grupo de enunciados e suas especificidades em um sistema de comunicação artístico que se dissolve no âmbito cotidiano (CAUQUELIN, 2005).

Apesar da demarcação do lugar e do tempo de onde se fala na presente discussão, não se pretende aqui abordar uma suposta 'evolução' na 'linguagem' do vídeo, ou estabelecer cronologias de 'desenvolvimento' nestas obras. Busca-se, sim, a 
compreensão sobre o constante aumento, com especial força na última década, de um número de objetos que falam de um mesmo espaço enunciativo, e que mais e mais se constituem enquanto grupo unido discursivamente. São objetos que se relacionam diretamente aos campos da indústria fonográfica e dos meios de comunicação de massa - por isto ainda o preconceito residual que permanece em sua observação -, mas, também, dos mecanismos de circulação da arte contemporânea. E é sobre este ponto que se reforça a importância da reflexão e, sobretudo, a importância da não exclusão destes vídeos como pertencentes a estas diversas instâncias; a importância de não ignorá-los.

Para desenvolver esta proposição, será utilizado como objeto de discussão o projeto "Valtari Mystery Film Experiment", realizado em 2012 pela banda islandesa Sigur Rós. Metodologicamente, procurar-se-á observar a descrição dos acontecimentos desta unidade discursiva (FOUCAULT, 2008): como apareceu este determinado enunciado, e não outro em seu lugar? O que os delimita, ou, que outros objetos falam a partir deste mesmo campo? E, neste caso, de que campo estamos falando?

\section{Valtari Mystery Film Experiment}

Nós nunca quisemos que nossa música viesse com uma resposta emocional pré-programada. Não queremos dizer a ninguém como devem se sentir e o que tirar das músicas. Com estes vídeos, literalmente não temos ideia do que os diretores irão trazer. Nenhum deles sabe o que os outros estão fazendo, então, provavelmente será uma experiência interessante (BIRGISSON, 2012) ${ }^{2}$.

Em 2012, a banda islandesa Sigur Rós lançou em seu website o projeto audiovisual The Valtari Mystery Film Experiment (Figura 1), com a produção de um conjunto de videoclipes para todas as músicas de seu álbum musical de nome homônimo, Valtari. Para cada diretor convidado, entre videoartistas e diretores de filmes, foi oferecido o montante de dez mil dólares, sem qualquer restrição ou indicação de assunto, meio ou ferramentas para o processo de construção das obras. A proposta do grupo foi que o processo criativo de cada diretor não sofresse, em nenhum momento, qualquer tipo de interferência. Além dos catorze vídeos produzidos pelos diretores, o público 
também pôde submeter suas próprias produções, que foram eleitas através de uma competição on-line, sendo um vídeo escolhido pela própria banda e o outro pelos espectadores.

Diretores de diferentes nacionalidades e formações participaram da realização de cada videoclipe, dentre os quais cabe destacar: Ragnar Kjartansson, islandês, músico, pintor, escultor, videoartista, produtor de instalações e performances, artista representante da Islândia na Bienal de Veneza nas edições de 2009 e 2013; Alma Har'el, israelense, diretora de filmes e videoclipes, vencedora do Tribeca Film Festival em 2011 com o documentário "Bombay Beach"; Melika Bass, norte-americana, com produções em vídeo e instalações site-specific, e obras exibidas no Museum of Contemporary Art de Chicago, Museum of Contemporary Art de Detroit e em festivais como o Torino Film Festival (Itália), Athens International Film Festival (Grécia) e Hamburg International Film Festival (Alemanha); Clare Langan, irlandesa, com trabalhos em fotografia, cinema e instalações de vídeo, realizou exposições de suas obras no MoMa, no Tate Liverpool, na $25^{\mathrm{a}}$ Bienal da São Paulo, na Bienal de Singapura de 2008, entre demais eventos e galerias, e foi premiada em 2007 no Oberhausen International Film Festival (Alemanha), com o filme "Metamorphosis"; Christian Larson, sueco, editor de videoclipes e comerciais, vencedor do Swedish Grammy Awards 2013 como Melhor Vídeo para a música "Valtari", integrante do projeto aqui estudado; Ramin Bahrani, norte-americano, diretor de filmes exibidos nos festivais cinematográficos de Veneza, Cannes, Sundance, Berlin e Toronto, e professor de direção no curso de Cinema da Columbia University; Ryan McGinley, fotógrafo norte-americano com exposições individuais no Whitney Museum (2003), no MoMA (2004) e no Museo de Arte Contemporáneo de Castilla y León (2005); Floria Sigismondi, fotógrafa e diretora de dezenas de videoclipes, e com mostra individual realizada no Museum of Contemporary Canadian Art (2001).

No total, dezesseis vídeos foram realizados, lançados avulsamente, a cada quinzena, de maio a dezembro de 2012 . Ficaram, desde então, hospedados em conjunto no website do grupo (www.sigur-ros.co.uk) e de maneira fragmentada em plataformas de conteúdo como YouTube e Vimeo. Após o lançamento de todos os vídeos, estas peças passaram a circular em diversos países em exibições que ora os colocavam como objetos avulsos, e ora como um projeto integral composto pela totalidade dos vídeos - caso do evento Music Video Festival (m.v.f.), organizado pelo Museu da Imagem e do Som de São 

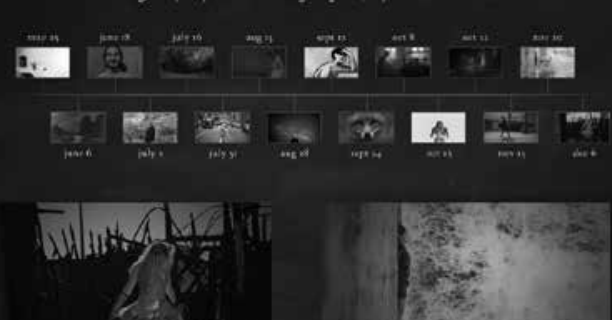

Paulo, em janeiro de 2013, que realizou exibição do projeto na íntegra. Nas divulgações para a imprensa, o grupo ressaltou a circulação do projeto em eventos pelos sete continentes - incluindo a Antártida -, e nos espaços mais distintos possíveis, de festivais e exposições a clubes musicais, lojas, espaços públicos e salões de beleza.

Cabe citar as proposições e procedimentos realizados por cada diretor no conjunto das obras: ora com narrativas de alguma maneira estruturadas ("Leaning Towards Solace", por Floria Sigismondi; "Fjögur Pianó", por Alma Har'el), ora com elementos da performance e da dança ("Vardeldur", de Melika Bass; "Valtari". de Christian Larson), vistas da natureza ("Daudalogn", de Henry Jun Wah Lee), pulsações e desconstruções no tempo da imagem ("Varud", de Inga Birgisdóttir), sobreposições de camadas visuais ("Vardeldur", de Clare Langan), o olhar sobre a cidade ("Varud", de Ryan McGinley) ou suspensões temporais de momentos ("Rembihnútur", de Arni \& Kinski). Os métodos de captação variam desde os que trabalham com as possibilidades da película $16 \mathrm{~mm}$, como Melika Bass, até a captação em ${ }_{4} \mathrm{~K}$ ou com câmeras de alta velocidade, como Clare Lagan e Henry Jun Wah Lee.

Neste cenário, uma dificuldade: falamos do presente, de algo que ainda está em circulação. Talvez justamente o que constitua uma das principais características da obra contemporânea, visto que esta se encontra em eterno estado de digestão, apropriação e recirculação. Podemos vir a isolar elementos - como o grupo musical, o tipo de música, os diretores
Figura 1

Website do projeto "Valtary Mystery Film Experiment”. 
convidados, os espaços em que estas obras circulam -, mas estes só farão sentido enquanto circuito em si, enquanto conjunto de relações. É esta a investigação a desenvolver.

\section{De onde se olha?}

Que se parta então do interior de elementos isolados para fora de seu campo. Um primeiro caminho investigativo nos aponta para o próprio grupo musical Sigur Rós, que nesta relação opera como o responsável pela 'encomenda' do produto mesmo que uma encomenda dita sem intervenção estética no processo do artista visual, ainda assim necessária em termos financeiros e de demanda para garantir a existência das obras.

Temos as informações: banda de experimentações em pós-rock, formada em Reykjavík, capital da Islândia, na década de 1990. Sua circulação no mercado fonográfico ocorre, desde então, através de selos de música independente - primeiro com a gravadora de nome irônico 'Bad Taste' (que significa 'mau gosto') e em seguida, onde permanece até hoje, na britânica XL Records, gravadora que trabalha com quantidades pequenas de lançamentos anuais (em média seis discos por ano, somando todos os artistas: quantidade muito menor do que demais gravadoras de grande porte). Possuem um estúdio próprio construído em Reykjavik, onde gravam e realizam a pós-produção de seus próprios álbuns - o que os afasta ainda mais de normatizações mercadológicas -, e com frequência aparecem em projetos transdisciplinares, como o "Split Sides" (2003), onde desenvolveram músicas para coreografia de Merce Cunningham (e participaram de uma série de apresentações ao vivo junto à Merce Cunningham Dance Company); o "PopRally" (2008), projeto do MoMA, onde se apresentaram ao vivo durante a exposição "Take your time: Olafur Eliasson"; e "Inni" (2011), documentário dirigido por Vincent Morisset, que registra a turnê homônima em Londres, e exibido no $68^{\circ}$ Festival Internacional de Cinema de Veneza; além do próprio "Valtari Mysteri Film Experiment", aqui discutido. Após a realização de Valtari, passaram a adotar uma abordagem mais interativa junto ao espectador, primeiro com "\#stormur", videoclipe gerado em tempo real a partir de pequenos trechos de vídeos enviados por usuários via Instagram, e em seguida com a turnê do disco "Kveikur", em 2013, onde realizaram convite aberto para que o público participante atuasse como crítico, escrevendo sobre cada apresentação em que estiveram presentes, gerando centenas de textos na página virtual da turnê. 
Observamos que a opção claramente transdisciplinar e que opta por uma liberdade de criação e circulação se faz presente na atuação do grupo, tanto musical quanto visualmente. No caso do "Valtari Mystery Film Experiment", isto se faz ainda com mais força: a partir de um disco lançado em condições atípicas (pois se encontrava 'guardado' e não finalizado há anos, arquivado entre outros projetos do grupo) e a partir de um selo musical independente, se chega a uma proposta de projeto visual atrelado a todas as músicas do disco, algo também inédito, visto que o procedimento padrão do mercado fonográfico é produzir videoclipes para duas ou três músicas de cada disco, mas raramente para todas as canções.

Grosso modo, poderíamos especular a princípio que estes músicos operam em uma espécie de curadoria particular, ao escolherem os diretores de quem querem se aproximar e a quem querem ter sua imagem vinculada. Mas este é um elemento já recorrente na indústria musical, tanto que determinados músicos trabalham apenas com um pequeno ou recorrente rol de diretores. A diferença aqui se funda na operação enquanto situação contemporânea do 'homem de gosto' de Agamben (2012) - afinal, não é esta mesma figura que considerava, a partir do século XVII, ação de 'mau gosto' intervir no trabalho do artista? Será então que a opção da não intervenção estética entre os músicos e os diretores acaba por legitimar estas obras no campo artístico, mesmo que não intencionalmente? Ou ao menos tira o 'peso' mercadológico da encomenda?

Uma vez que o questionamento suscitado na observação a partir dos músicos acaba por esbarrar em um âmbito por demais especulativo - de qual seria a 'intenção' de uma das partes -, poderíamos então abandonar por um instante esta via e caminhar por outro sentido de abordagem: o de que estas obras se colocam como arte porque foram criadas e dirigidas por determinados videoartistas, conforme já citado, cujos trabalhos já circulam em galerias, museus e espaços expositivos. O fato de estes nomes estarem vinculados aos videoclipes já imprimiria a estes objetos seu caráter artístico, por carregarem implicitamente a subjetividade e o histórico de cada realizador. Esta observação parece interessante à primeira vista, mas parece não dar conta das relações entre instâncias: são obras de artistas já reconhecidos pelo circuito artístico - e este é seu denominador comum -, mas obras pensadas desde o início para um circuito diferente, sem qualquer materialidade do espaço do museu ou da sala de projeção - obras de um circuito virtual. São também obras em que, mesmo sem que um reali- 
zador soubesse da intenção do outro, no momento de sua produção, acabam como um conjunto que partilha inconscientemente de um mesmo enunciado. Por exemplo, nestas obras, a apropriação da materialidade e movimento do corpo é sempre presente, e quando não sobre o corpo humano, ainda assim sobre a fisicalidade da natureza. Observamos a recorrência da dança contemporânea, o trabalho constante de pós-produção na colorização destas obras, e o tempo expandido dos planos na montagem. Mas, de que maneira aproximar estas obras, considerando sua motivação e demanda para existência - a encomenda -, do campo da arte contemporânea? Cauquelin (2005) apresenta alguns indicativos norteadores:

Para apreender a arte como contemporânea, precisamos, então, estabelecer certos critérios, distinções que isolarão o conjunto dito 'contemporâneo' da totalidade das produções artísticas. Contudo, esses critérios não podem ser buscados apenas nos conteúdos das obras, em suas formas, suas composições, no emprego deste ou daquele material, também não no fato de pertencerem a este ou aquele movimento dito ou não de vanguarda (p. 12).

Buscando critérios que se aproximem desta compreensão, uma terceira via - e esta é a que parece, mesmo que não esgote ou resolva definitivamente, ao menos indicar caminhos - permite estabelecer relações entre músicos, videoartistas e a existência destas obras como diretamente inseridas no campo da reprodutibilidade técnica. É a abordagem sobre a reorganização da circulação na contemporaneidade, prevista por Malraux e indicada por Hal Foster:

Resumindo, onde Benjamin via a ruptura definitiva do museu forçada pela reprodutibilidade técnica, Malraux via sua expansão definitiva. Se para Benjamin a reprodutibilidade técnica destrói a tradição e liquida a aura, para Malraux provê meios de reorganizar os pedaços quebrados de tradição em uma metatradição de estilos globais - um novo museu sem paredes cujo tema é a família do homem (FOSTER, 2002, p. 189).

Novamente, Cauquelin (2005) proverá subsídios em sua discussão sobre a transição do regime artístico moderno para o contemporâneo. Se a onipresença do consumo em uma era industrial regia a arte moderna, através de um mecanismo de demanda ativado por intermediários - marchands, críti- 
cos, instituições -, através do 'isolamento' da figura do artista como uma figura singular (alheia ao processo de produção/ circulação e muitas vezes com ideologia política bem definida), através do autoconsumo entre seus diletantes e colecionadores (que compram pelo 'prazer de ter um olho clínico') e através da separação entre estes diletantes e a massa do 'público comum' (a quem cabe de fato o reconhecimento e opinião sobre a obra), a ruptura contemporânea vem acompanhada por mudanças neste mecanismo. Passa, com grande intensidade, dos processos de consumo aos processos de comunicação. E tem como característica principal o apagamento da noção de 'sujeito' que comunica "em favor de uma produção global de comunicações".

No projeto "Valtari", este sistema que digere automaticamente informações extras geradas é visível; para isto, basta colocar que, além das circulações globais, físicas ou virtuais já mencionadas, os espaços de distribuição de conteúdo on-line, como o YouTube, comportaram um envio massivo de conteúdos por parte de artistas que não foram selecionados oficialmente pela banda, mas que produziram seus próprios vídeos para músicas do álbum e se autoincluíram na circulação. $\mathrm{Ou}$ seja, além dos dezesseis vídeos oficiais produzidos sob encomenda, dezenas de outras obras se vincularam ao projeto extraoficialmente, por diretores (iniciantes ou não) que também queriam partilhar suas respectivas obras visuais a partir das músicas. Não se trata de situar necessariamente estes vídeos extraoficiais também no campo da arte, mas de indicar a circularidade total carregada pelo projeto original. Sua procura por ubiquidade demonstra seu princípio: "Quando vemos uma obra dita 'de arte contemporânea, estamos vendo na verdade a arte contemporânea em seu conjunto. Ela mesma se apresenta em seu processo de produção" (CAUQUELIN, 2005, p. 74).

Nesta individualização de um projeto que se destaca em meio a uma massa virtual de outros videoclipes que circulam de maneira idêntica, sua renovação - uma "versão contemporânea do antigo sistema de vanguarda que caracterizava a arte moderna" (p. 76) - não deixa de estar ligada às relações do grupo musical com a indústria fonográfica ou às poéticas e práticas dos artistas convidados, mas, sobretudo, é consequência do próprio sistema. Sistema que 'descobre' estas obras, não mais unicamente pela figura do curador, mas pelo grande e fragmentado montante de 'colecionadores virtuais' - público que se apropria diariamente de novos objetos, que torna a obra elemento constitutivo desta rede, e sem o qual nem 
a obra nem o artista adquirem existência visível. E o museu, inserido ao fim desta circularidade, exibe estas imagens por serem seu próprio valor de espetáculo, onde o arquivo eletrônico é utilizado para aumentar o culto e a aura da obra (FOSTER, 2002, p. 190).

É importante apontar a controvérsia no sistema de circulação deste projeto de videoclipes: o projeto é apreendido da rede para a exposição, conferindo nova 'realidade' ao simulacro do vídeo. Ou seja, um projeto que em si operava enquanto obra de arte desde o momento de sua criação, é ressignificado após o deslocamento de seu meio natural - a internet - para o museu. Como se, a partir deste momento, uma obra que já existia no domínio da arte passasse a integrar institucionalmente o campo da arte contemporânea. Cauquelin (2005) discute esta situação:

Curiosamente, quando um grande barulho está sendo feito em torno da análise dos processos de comunicação [...] e quando se aperfeiçoam as práticas sustentadas por esses sistemas, a arte parece continuar fora de qualquer análise consistente da mudança e da perspectiva. Fato ainda mais estranho, as práticas artísticas absorveram bastante essa modificação, mas não suscitam nenhum comentário que as leve em conta para reformular os princípios de seu exercício. [...] O mundo da arte, como outras atividades, foi sacudido pelas 'novas comunicações'; sofre seus efeitos, e parece leviano tratar esses efeitos como mutações superficiais (2005, p. 56).

O "Valtari Mystery Film Experiment" não pode ser considerado videoarte 'contaminada' por uma linguagem televisiva, e tampouco obra audiovisual com 'elementos de videoarte', pois partilha de outro sítio, outro espaço, que em muito já superou a circulação televisiva: ela é o próprio circuito, que dá novos usos aos dispositivos de imagem (o notebook, o celular, o tablete, e também o monitor exposto no museu e o projetor cinematográfico). É um projeto inserido em uma configuração comercial, como a maior parte da produção contemporânea, existente graças a relações transdisciplinares e à circulação global, e que se aproxima de instituições artísticas ou culturais e as agrega nesta circularidade.

Se ainda não plenamente compreendido nas reflexões acadêmicas como obra do campo artístico, até pela própria falta de entendimento geral sobre as tecnoimagens, trabalhos como 
o aqui apresentado esperam poder trazer novos olhares para as relações entre as superfícies em que este projeto aparece, e onde se encontram outros tantos projetos ainda não analisados. Agrupá-los conforme a especificidade de suas práticas:

Apesar de todas essas relutâncias frívolas, a arte nascida das tecnologias de comunicação segue seu caminho, mesmo que fora da sociedade bem pensante. Ela encontra apoio entre os que têm interesse em seu desenvolvimento: os industriais, as grandes empresas internacionais de microeletrônica, os produtores de filmes, ou simplesmente os pesquisadores de informática [...]. Se as tecnoimagens e seus desenvolvimentos pudessem ajudar a redefinir o que é a arte, seu sítio, seus objetos e seus atores, reunindo assim o trabalho empreendido pelos próprios artistas em seu próprio sítio, já seriam detentoras de todas as virtudes 'estéticas' desejáveis - aquelas do domínio da crítica. Sem falar de vanguarda, seriam realmente a parte viva da arte contemporânea (CAUQUELIN, 2005, p. 159-160).

\section{NOTAS}

1. Este trabalho teve o apoio da FAPESP (Fundação de Amparo à Pesquisa do Estado de São Paulo), através de bolsa de Doutorado do processo $2013 / 02497-0$.

2. Depoimento de Jón Pór Birgisson, vocalista do grupo Sigur Rós, em declaração no website oficial da banda, em 2012.

\section{Referências}

AGAMBEN, Giorgio. O homem sem conteúdo. Belo Horizonte: Autêntica, 2012.

CAUQUELIN, Anne. Arte Contemporânea: uma introdução. São Paulo: Martins Fontes, 2005.

FOSTER, Hal. Archives of Modern Art. In: FOSTER, Hal. Design and Crime. Londres e Nova York: Verso, 2002.

FOUCAULT, Michel. A arqueologia do saber. Rio de Janeiro: Forense Universitária, 2008.

\section{Websites}

Music Video Festival. Disponível em: <http://www.musicvideofestival.com.br>. Acesso em: 30 mar. 2014. 
Split Sides - Sigur Rós e Merce Cunningaham Dance Company. Disponível em: <http://sigur-ros.co.uk/band/disco/split. php>. Acesso em: 30 mar. 2014.

The Museum of Modern Art (MoMA) and MoMA PS1 PopRally. Disponível em: <https://www.moma.org/poprally>. Acesso em: 30 mar. 2014.

Valtari Mystery Film Experiment. Disponível em: <http:// sigur-ros.co.uk/valtari/videos>. Acesso em: 30 mar. 2014.

Recebido em: 31/o3/14

Aceito em: 21/07/14 


\section{LIENE NUNES SADDI}

lienesaddi@gmail.com

É doutoranda em Artes Visuais (Multimeios e Arte) pela Unicamp, e docente no curso de Produção Audiovisual, nas Faculdades Integradas de Bauru (FIB). Desde sua graduação em Comunicação Social (Midialogia) pela Unicamp (2007), atuou como produtora audiovisual na programação da TV Unesp, e como animadora cultural no SESC Bauru, onde foi responsável pelas áreas de Artes Visuais/Arte-mídia. 